Research Article

\title{
Forecast of Thunderstorm Cloud Trend Based on Monitoring Data of Thunder Mobile Positioning System
}

\author{
Mingfa $W u\left(\mathbb{D},,^{1,2}\right.$ Chongjing Yang $\mathbb{D}^{1,3}$ and Xiangke Liu ${ }^{2}$ \\ ${ }^{1}$ Shandong Provincial Key Laboratory of Meteorological Disaster Prevention and Reduction, Jinan 250031, Shandong, China \\ ${ }^{2}$ Shandong Meteorological Disaster Prevention Technology Center, Jinan 250031, Shandong, China \\ ${ }^{3}$ Technical Support Center for Atmospheric Sounding of Shandong Meteorological Bureau, Jinan 250031, Shandong, China
}

Correspondence should be addressed to Chongjing Yang; yangchong0706@163.com

Received 8 June 2021; Revised 13 July 2021; Accepted 13 August 2021; Published 20 August 2021

Academic Editor: Sang-Bing Tsai

Copyright ( $\odot 2021$ Mingfa Wu et al. This is an open access article distributed under the Creative Commons Attribution License, which permits unrestricted use, distribution, and reproduction in any medium, provided the original work is properly cited.

\begin{abstract}
As a natural phenomenon, thunder and lightning have a major impact on human production and life. As an important part of lightning protection technology, the main task of the lightning mobile positioning system is to detect and determine the location of lightning and, at the same time, provide more accurate lightning discharge parameters for lightning research. It is a new technology that serves the entire society and is in urgent need of development. This paper aims to study the trend prediction of thunderstorm cloud based on the monitoring data of the thunder and lightning mobile positioning system. In this thesis, the inverse distance-weighted interpolation method can be used to determine the lightning area and the principle of lightning monitoring and positioning, and the classification of lightning and the practical significance of lightning mobile positioning system monitoring are also studied. Finally, the Hurst index of this paper can reveal the trend elements in the time series well through the experiment, so as to judge the lightning strikes. At the same time, it also introduces everyone's satisfaction survey on the lightning mobile positioning system. The results of this paper show that the lightning mobile positioning system has been widely used in our country's meteorological monitoring stations, and it plays a very important role in our national defense lightning strikes and effectively realizes the lightning strike prediction in the monitoring process, which can better enable the competent department to take timely and accurate measures to prevent lightning strikes. Experimental analysis shows that the accuracy of the lightning mobile positioning system has reached $92 \%$, and the practicability has reached $88 \%$.
\end{abstract}

\section{Introduction}

1.1. Background of Topic Selection. Since the reform and opening up, the rapid economic growth has led to steady growth in demand. My country's existing capabilities have become the first in the world. In order to meet the everincreasing demand for electricity, the scale of my country's power grid is constantly expanding and the voltage level is also constantly increasing. High-voltage transmission can effectively reduce power loss and save transmission costs. However, due to the long duration of the high-voltage transmission line and the high grounding distance, this also increases the lightning on the high-voltage transmission line. The areas with severe thunder and lightning in China are mainly distributed in the coastal areas of East China and
South China. Lightning accidents in this area account for $45 \%$ of the total lightning accidents in our country. According to statistics, the number of trips of lightning highvoltage transmission lines in my country accounts for $40 \%$ to $70 \%$ of the total number. Thunder and lightning will cause not only line interruption and power interruption but also the intrusion of lightning into the substation which can damage the insulation of the primary electrical equipment or damage the secondary equipment, resulting in peripheral power outages. Traditional lightning protection measures for power grids mainly include reasonable selection of line corridors, reduction of tower grounding resistance, construction of lightning rods, and installation of lightning rods. The purpose is to reduce the spread of lightning when lightning strikes the line. Although these methods have 
achieved remarkable results, they are very susceptible to the influence of geographical environment and cannot give the law of lightning strike density and frequency of lightning strikes in a specific area with the occurrence and disappearance of thunderstorms. This is the key to affecting the real-time lightning strike probability of transmission lines.

1.2. Significance of the Research. The lightning mobile positioning system is extremely important for lightning research, monitoring, and protection. On the one hand, the system can provide lightning discharge parameters on a large scale and with high precision, providing a scientific basis for lightning scientists to further study the characteristics of lightning discharge and more refined physical processes. On the other hand, through real-time monitoring of events, developments, disasters, traffic directions, and other storm activity characteristics, some key protection projects can be monitored and predicted similar to hurricanes and disasters to minimize potential losses. In the third aspect, thunder and lightning are often strongly associated with severe weather conditions (such as heavy rain and hail). Therefore, monitoring the range, intensity, and frequency of lightning is an important tool for monitoring and predicting the abovementioned weather disasters. In the fourth aspect, lightning monitoring and precise installation have extremely high economic benefits by helping to investigate lightning damage points in the power system, locating and monitoring lightning and fire damage, and warning satellites to launch lightning strikes. At present, almost all developed countries and regions have established lightning monitoring and resettlement networks within the country and region.

\subsection{Relevant Work on the Monitoring Data of the Lightning} Mobile Positioning System. Nowadays, the lightning mobile positioning system has been widely used in our country's weather monitoring stations, and it plays a very important role in our national defense lightning strikes. It effectively realizes the lightning strike prediction in the monitoring process, which can better enable the competent department to take timely and accurate measures to prevent lightning strikes. Based on the principle of the lightning hybrid constraint algorithm, Dobrev et al. introduced the framework, main features, development, and application of the Shaoxing lightning positioning system. The analysis results show that, as a complex detection network with multiple functions (lighting detection, positioning, and data processing), the system can locate lightning relatively correctly, and the detection data can be used in a variety of applications. Through the analysis of these data, the formation and evolution of lightning can be found, which will help forecast early warning of lightning and lightning disasters [1]. However, the research did not use the lightning mobile positioning system, which made the research data inaccurate. Kim et al. used the lightning data of the Jiangxi Province Lightning Monitoring and Positioning System from 2014 to 2020 to analyze the distribution characteristics and correlation coefficients of the lightning intensity and steepness in Jiangxi Province. The analysis shows that there is a significant difference between the annual average lightning strike density calculated based on the measured value and the calculated annual average lightning strike density. The number of days of thunderstorms was observed in [2]. Moosavi et al. evaluated the use of precipitable water (PW) in the global positioning system (GPS) in lightning prediction. This earlier model used the binary logistic regression analysis and best selected the following four predictors from a candidate list of 23 candidate predictors: the current level of sedimentable water at a given time of day, past 9 hours GPS PW changes, indicators, and electric field grinding values. This index is used as a measure of atmospheric stability. In the traditional stability measurement, the index has shown the best effect in the studied region and season. This early model is not optimized for any specific forecast interval, but it shows the promise of 6-hour and 1.5hour forecasts [3]. However, the research did not use the lightning mobile positioning system, which made the research data inaccurate.

\subsection{Innovation Points of This Research.}

(1) The Raiden mobile positioning system has the characteristics of safety, accuracy, low cost, and practicality. And, the lightning mobile positioning system can predict the arrival of lightning in advance so that it can reduce the harm and bring everyone a sense of security.

(2) The questionnaire survey method used in this article is mainly conducted at the weather station. The weather station is based on the research on the forecast of thunderstorm cloud trend based on the full monitoring data of the lightning mobile positioning system and is used for the comparison and observation of the propaganda of the lightning mobile positioning system.

\section{Method for Monitoring Data of the Lightning Mobile Positioning System}

2.1. Overview of the Development of Lightning Monitoring Technology. In the early 1980s, with the development of lightning physics, electronics, and computer technology, American scientists first introduced a multistation surveillance system that can receive low-frequency electromagnetic pulses generated by lightning. French scientists introduced interferometers for VHF lightning monitoring systems in the mid-1990s. In China, the Chinese Academy of Sciences, the Space Application Center, the 22nd Institute of Electronics of the Ministry of Information Industry, the University of Science and Technology of China, and the Wuhan High Voltage Research Institute have also begun to develop monitoring systems [4]. In the 1980s, its own characteristics were gradually shaped. The lightning movement positioning theory refers to the principle and method of remote measurement of lightning discharge parameters using the electromagnetic field reflected by sound, light, and flicker radiation. The current main lightning monitoring mobile positioning methods are as follows: 
(1) Acoustic method: use the ultrasonic waves emitted during lightning to determine the position of the lightning monitor [5].

(2) Optical method: determine the parameters of the flyback discharge by measuring the brightness and spectral elements of the lens [6].

(3) Electromagnetic field method: use the electromagnetic wave signal emitted. At present, the main installation technologies are divided into two types: multiposition installation and single-position installation [7].

Single-stage positioning systems have three measurement methods, while multistation positioning systems can be divided into two methods: low-frequency lightning monitoring and high-frequency lightning monitoring, as shown in Table 1.

\subsection{Principles of Lightning Monitoring and Positioning.} The lightning positioning system designed in this paper uses a multistation lightning system based on the TOA method, which consists of multiple lightning receiving stations distributed in a specific area of approximately a radius and a central control system [8]. What this article needs to design and implement is the collection and processing of lightning electromagnetic signals, so this section first explains the principles of design and implementation [9].The lightning mobile positioning system is currently the most advanced and new real-time lightning tracking system. Predicting lightning activities can effectively reduce the damage of lightning to high-tech equipment in the electronic communication system, thereby reducing lightning activities.

By collecting the time when the electromagnetic wave signal is generated when a lightning event occurs, it arrives at each detection station, calculates the time difference between these stations, and receives the three-dimensional position and time of the lightning event [10]. Time-of-arrival (TOA) detection is a multistation lightning positioning system that uses the time difference of electromagnetic waves to reach various lightning detection stations to detect lightning. Therefore, the standard time difference between different positions (i.e., the synchronization of positions) determines the placement accuracy of the entire system. At the same time, because the collected signal is a radio frequency signal, a large number of radio waves interfere with the propagation in the air, so in this positioning system, the time synchronization of each station is the most important [11]. The schematic diagram of the TOA detection method is shown in Figure 1:

As shown in Figure 1, when a lightning pulse occurs, the radiated electromagnetic wave signal has four unknown factors, namely, the three-dimensional position and the absolute time of the beginning [12]. Since the arrival time of the event at each location is different, it will first be transmitted to the site closest to the lightning event and then to the farthest site. The propagation speed of electromagnetic waves is certain, so there must be

$$
c\left(t-t_{i}\right)=\sqrt{\left(x-x_{i}\right)^{2}+\left(y-y_{i}\right)^{2}+\left(z-z_{i}\right)^{2}} .
$$

According to the above formula,

$$
t_{i}=t+\frac{1}{c} \sqrt{\left(x-x_{i}\right)^{2}+\left(y-y_{i}\right)^{2}+\left(z-z_{i}\right)^{2}} .
$$

Among them, $c$ is the signal propagation speed, and $\left(x_{i}, y_{i}, z_{i}, t_{i}\right)$ is the three-dimensional position of the $i$ th station, that is, the time when the electromagnetic wave arrives at the $i$ th station.

Definition:

$$
\begin{aligned}
& r_{i}^{2}=x_{i}^{2}+y_{i}^{2}+z_{i}^{2}, \\
& r^{2}=x^{2}+y^{2}+z^{2} .
\end{aligned}
$$

We can obtain

$$
c^{2}\left(t^{2}+t_{i}^{2}\right)=r^{2}+r_{i}^{2}-2\left(x x_{i}+y y_{i}+z z_{i}+c^{2} t t_{i}\right) \text {. }
$$

Replacing $i$ in equation (5) with $j$ and subtracting equation (5), we obtain

$$
\begin{aligned}
c^{2}\left(t_{i}^{2}-t_{j}^{2}\right)-\left(r_{i}^{2}-r_{j}^{2}\right)= & -2\left[x\left(x_{i}-x_{j}\right)+y\left(y_{i}-y_{j}\right)\right. \\
& \left.+z\left(z_{i}-z_{j}\right)-c^{2} t\left(t_{i}-t_{j}\right)\right] .
\end{aligned}
$$

Definition:

$$
\begin{aligned}
t_{i j} & =t_{i}-t_{j}, x_{i j}=x_{i}-x_{j}, \\
y_{i j} & =y_{i}-y_{j}, \\
z_{i j} & =z_{i}-z_{j} .
\end{aligned}
$$

Thus,

$$
\frac{\left(r_{i}^{2}-r_{j}^{2}\right)-c\left(t_{i}^{2}-t_{j}^{2}\right)}{2}=x x_{i j}+y y_{i j}+z z_{i j}-c^{2} t t_{i j} .
$$

Let

$$
q_{i j}=\frac{\left(r_{i}^{2}-r_{j}^{2}\right)-c\left(t_{i}^{2}-t_{j}^{2}\right)}{2} .
$$

Then, there is

$$
q_{i j}=x x_{i j}+y y_{i j}+z z_{i j}-c^{2} t t_{i j} .
$$

From equation (10), a set of linear equations about $(x, y$, $z, t)$ can be obtained. Through matrix representation, we obtain

$$
\left[\begin{array}{cccc}
c t_{i j} & x_{i j} & y_{i j} & z_{i j} \\
c t_{i k} & x_{i k} & y_{i k} & z_{i k} \\
c t_{i l} & x_{i l} & y_{i l} & z_{i l} \\
c t_{i m} & x_{i m} & y_{i m} & z_{i m}
\end{array}\right] \cdot\left[\begin{array}{c}
-c t \\
x \\
y \\
z
\end{array}\right]=\left[\begin{array}{c}
q_{i j} \\
q_{i k} \\
q_{i l} \\
q_{i m}
\end{array}\right] .
$$

Solving this matrix equation may affect the arrival time, which is the location of the lightning event. 
TABLE 1: Classification of lightning monitoring methods.

Single station positioning system

Receiving frequency band: low-frequency electromagnetic pulse and very high-frequency band

Direction finding: gated cross-loop direction finding technology, $T$, interferometer method Ranging: Intensity distance, spectrum method, electromagnetic component correlation method, and hybrid method

Low-frequency lightning monitoring

Multistation positioning system
Azimuth intersection positioning

Time difference of arrival positioning Comprehensive positioning of azimuth intersection and time difference

Interferometric direction finding Multistation positioning

High-frequency lightning monitoring
Comprehensive positioning of time difference and azimuth intersection

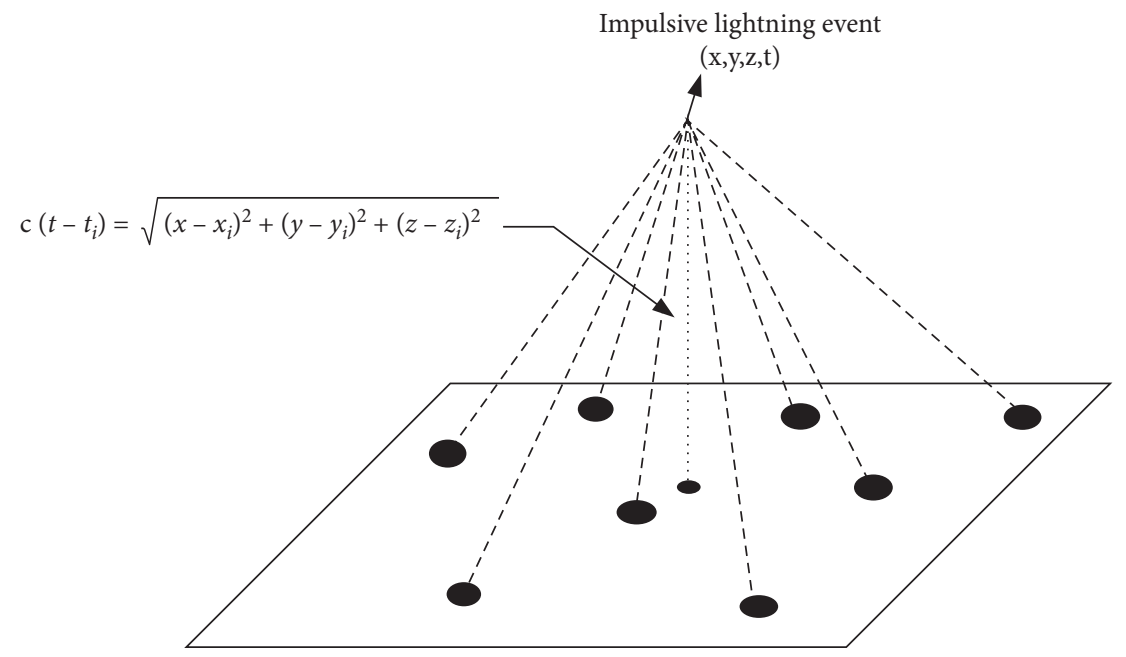

FIGURE 1: Schematic diagram of TOA monitoring.

2.3. Inverse Distance-Weighted Interpolation Method. Use discrete lightning coordinates to determine the lightning strike area. Boundary delimitation and interpolation methods can be used. Because the interpolation method can more accurately describe the lightning density at any position in the selected area within a period of time according to different lightning density distributions, it is adaptable to storms, and cloud limits determine the characteristics [13]. Therefore, this document chooses the reverse weighted interpolation method to determine the area covered by storm clouds.

The inverse distance-weighted interpolation method is based on the principle of similarity, that is, the closer the two objects are, the more similar their attributes are. It uses the distance between the insertion point and the sampling point as the weight for performing a weighted average [14]. The closer the sample point is to the insertion point, the greater the weight given to it. The general formula of the inverse distance-weighted interpolation method is as follows:

$$
\widehat{Z}\left(s_{0}\right)=\sum_{i=1}^{N} \lambda_{i} Z\left(s_{i}\right),
$$

where $\widehat{Z}\left(s_{0}\right)$ is the predicted value in $s_{0}, N$ is the number of samples around the predicted point to be used in the prediction calculation process, $\lambda_{i}$ is the weight of each sample point used in the prediction calculation process [15], and $Z\left(s_{i}\right)$ is the measured value in $s_{i}$. The calculation formula for determining the weight is

$$
\begin{aligned}
\lambda_{i} & =\frac{d_{i 0}^{-p}}{\sum_{i=1}^{N} d_{i 0}^{-p}}, \\
\sum_{i=1}^{N} \lambda_{i} & =1,
\end{aligned}
$$

where $P$ is the index value and $d_{i 0}$ is the distance between the predicted point and each known sample point.

\subsection{Platform Design of Lightning Monitoring and Positioning} System. The whole system is composed of signal acquisition and lightning transmission subsystem, data processing, and integration center. As shown in Figure 2, the work performed in this document only includes the lightning collection and transmission subsystem [16]. The Raiden mobile positioning system has safety, accuracy, low cost, and practicality. The main function of the signal acquisition and transmission subsystem is to collect electromagnetic wave signals during lightning strikes, convert them into digital 


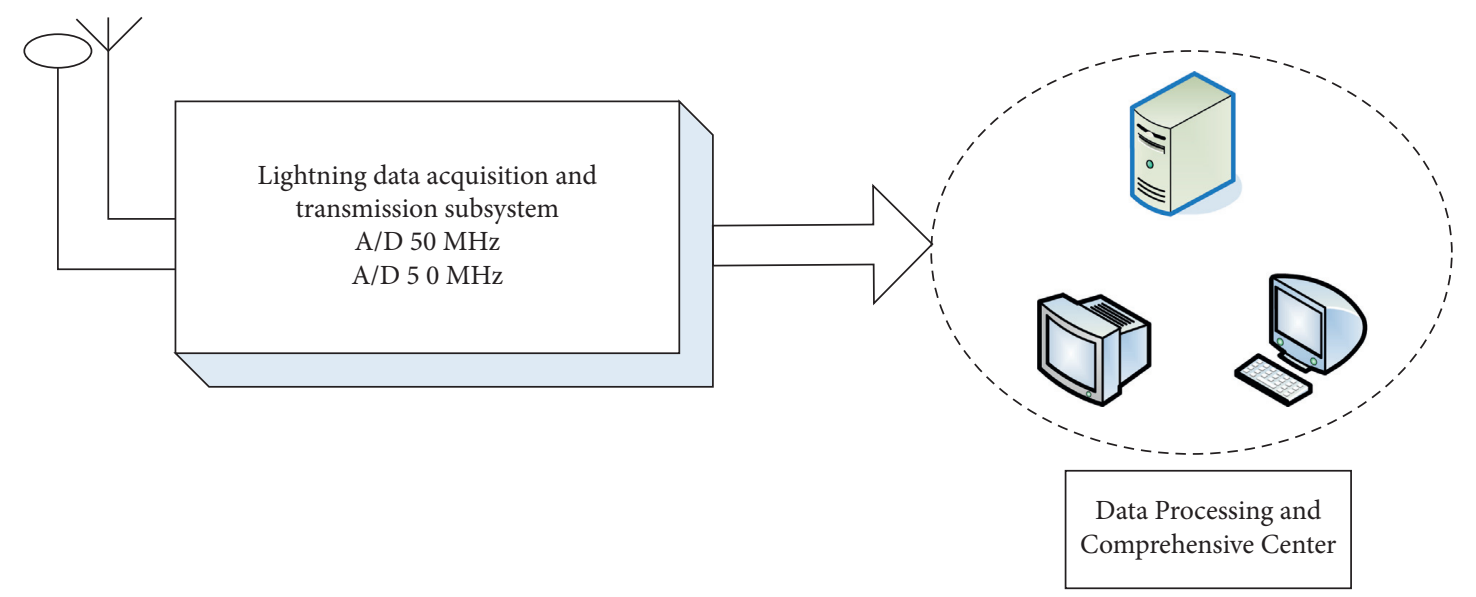

FIGURE 2: Lightning positioning system overall block diagram.

signals, and select and store the required data, or directly transmit them to the central information location in data processing and integrated production [17].

Since the back-end data center processes multisite data together, the synchronization between the sites and the accuracy of the calibration time of each site are required to be very high, and the clock signal of the entire system is required to be strictly stable $[18,19]$. Therefore, the frequency calibration unit is a very important part of the system. It is designed to strictly control the clock displacement generated by the crystal-controlled voltage oscillator on the hardware board when performing functions such as high-frequency and low-frequency data processing. According to the received second pulse signal, the system calculates the actual clock frequency generated by the controlled voltage crystal oscillator in the second time interval between the two adjacent second pulse signal rising ends and sends the actual clock frequency out. The calculated data of the actual clock frequency provides voltage adjustment of the controlled crystal oscillator voltage from the frequency of the voltage-controlled crystal oscillator and the frequency deviation between the clock and the driver to correct the actual clock of the crystal oscillator voltage controlled by the clock oscillation frequency. The pulse signal as a reference frequency also solves the problem of synchronization between stations [20].

The lightning signal acquisition subsystem designed based on the above design scheme includes antenna, preamplifier and filter, AD, CPLD, GPS, ARM core board, and other hardware modules. The system block diagram is shown in Figure 3.

\subsection{Classification of Lightning}

2.5.1. Direct Lightning Strike. A direct lightning strike is an electrical discharge between the clouds and the ground ledge that will immediately form a lightning strike. An instant lightning strike will immediately injure and kill people and animals. Thereby generating extremely high voltages on the ground at the lightning strike point and the metal parts connected to it, which may cause direct contact voltage or step voltage accidents [21].
2.5.2. Spherical Mine. Spherical mine is a spherical, red, or extremely bright white fireball. Spherical lightning can invade the room from doors, windows, chimneys, and other passages, which is extremely dangerous [22].

2.5.3. Induction Mine. Lightning induction is divided into electrostatic induction and electromagnetic induction. Electrostatic induction is caused when lightning strikes close to the ground, creating a large opposite-sex charge at the top of the rock wall. After removing the thundercloud and other components, the charge on the top of the window sill loses its self-control and moves along the window sill extremely quickly in the form of lightning [23]. Electromagnetic induction is caused by lightning current, which will produce a rapidly changing strong magnetic field in the surrounding space after a lightning strike. This type of magnetic field can cause high voltages in nearby metal conductors, which can lead to secondary discharges in the human body and damage electrical equipment [24].

2.5.4. Lightning Intrusion Wave. The lightning intrusion wave refers to the lightning wave that rapidly propagates along the line or pipeline due to the impulse voltage generated by the lightning strike on the overhead line or the metal pipeline in the sky [25]. Lightning strikes can damage the insulation of electrical equipment, cause high-voltage to low-voltage currents, and cause serious electric shock accidents.

2.5.5. The Relationship between Lightning and Electric Field Strength. By monitoring the value of the electric field strength at a certain point, the cloud activity and cloud charge can be monitored at a certain distance above the local area, and lightning prediction and warning can be realized. Because when there is thunder, the force of the atmospheric electric field on the Earth's surface will change. When the cloud height is low and the amount of charge is high, it is more likely to be discharged to the ground. Therefore, the ground electric field meter can be used to analyze the electric 


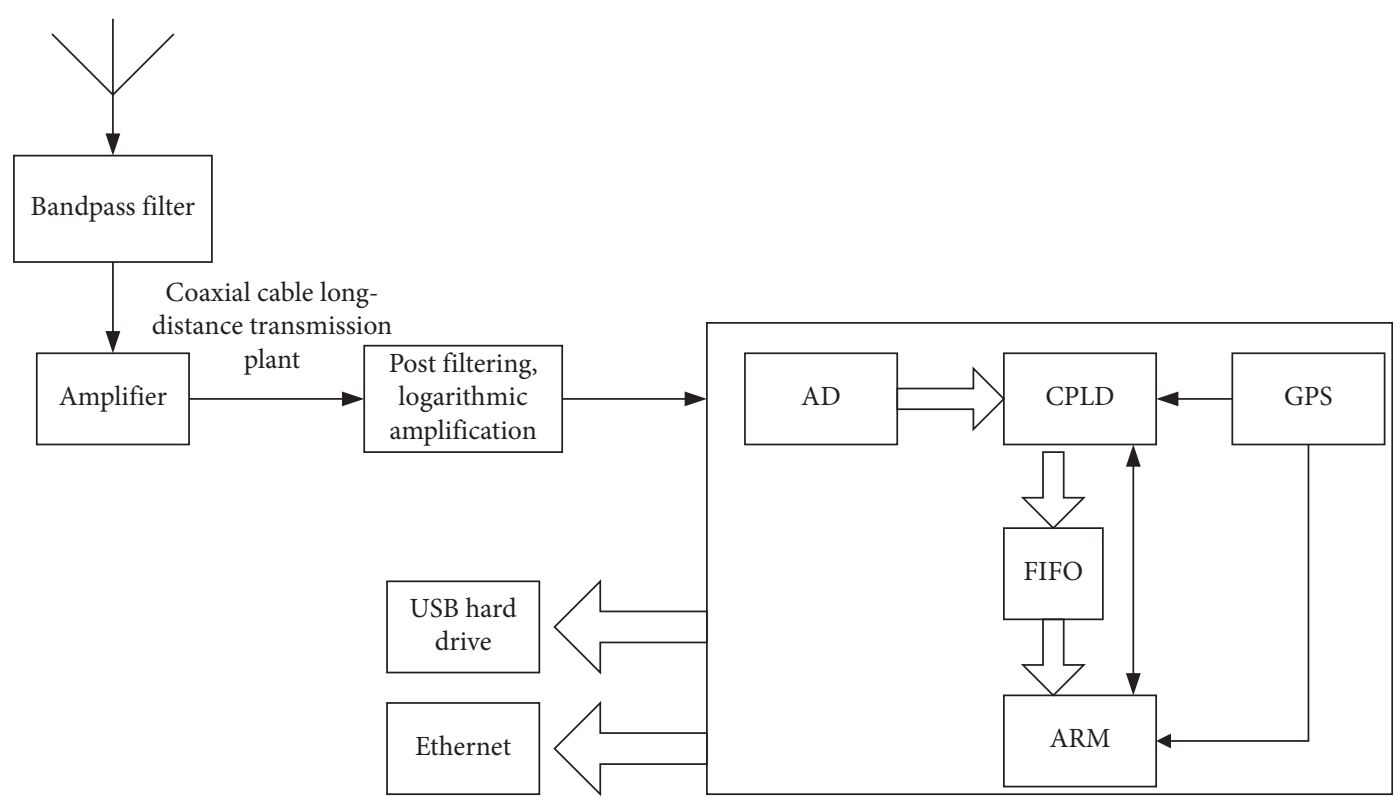

FIGURE 3: Data acquisition and transmission subsystem block diagram.

field strength. The probability of a lightning strike near a point on the ground is proportional to the electric field strength at that point [26]. When a specific point has a relatively large field strength electric field, the distance to that point is shorter. Lightning is more likely to occur within this range. As the height of the cloud decreases, the amount of charge increases, and as the distance from the electric field meter decreases, the intensity of the electric field detected by the electric field meter will increase. Moreover, the electric field intensity at this time is inversely proportional to the distance between the lightning position and the electric field meter. In this way, the electric field meter can warn appearance of lightning at a certain distance.

When a certain cloud layer reaches a certain level of charge, they will be evacuated between the clouds and between the clouds and the ground. The discharge between clouds is called cloud flash, and the discharge between clouds and the Earth is called cloud-to-ground flare. The discharge time between clouds is usually very short and the energy is not large because the discharge distance between clouds is short, and the discharge and the sound and light effect are not obvious, and the discharge distance between clouds is also very far from the area of human activities, so it is not the impact of human activities that is very small. The phenomenon of evacuation between the cloud and the Earth is called lightning from the cloud to the ground. Due to the low electric potential of the clouds relative to the ground, when it reaches a certain strength, the electric field between them is very low, and the negatively charged particles will accelerate to the ground, which is igniting lightning. The ionized electrons in the air move at high speed, and this path has the ability to conduct electricity. The lightning speed is quite fast, but the brightness is not high. Each lightning has a certain distance, will stop for a while, and then change the direction; repeating this way, forming a winding road, the route is completely negative. When the lead lightning approaches the ground, a strong electric field is formed. When a large number of positive poles rise, the negative pole charge in the channel and the air will drop, and a large amount of energy will be released at the same time. This process is called a counterattack. The schematic diagram of the lightning pilot and the pilot lightning is shown in Figure 4:

2.6. Harm of Lightning. The harm of thunder and lightning is great, and the scope of influence is wide. According to incomplete statistics, there are countless lives and property losses caused by lightning strikes in the world every year, and flashes from the ground to the ground cause the most serious harm to humans. After lightning strikes the power grid, a large area of electrical equipment will be destroyed and lifethreatening. The rapid decline in lightning capacity of equipment is one of the negative effects caused by the rapid development of modern electronic technology and its wide application in various industries. Lightning has become one of the most important natural disasters that endanger the lives and property of our people. Every year, more than 4,000 people in our country are injured or killed by lightning, and the direct economic loss exceeds several billion yuan. The harm caused by lightning to various industries is shown in Figure 5:

2.7. Practical Significance of Lightning Mobile Positioning System Monitoring. Every year, lightning and thunderstorms cause many losses to our lives and property. Therefore, it is necessary to establish a reliable and effective lightning monitoring and early warning system. At the same time, the system can also help us study the characteristics and distribution of lightning to avoid lightning. The disasters they bring to people's lives play a vital role. 


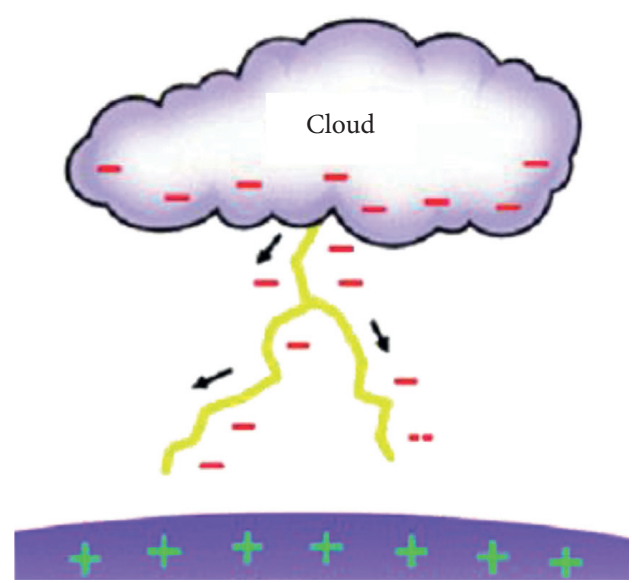

(a)

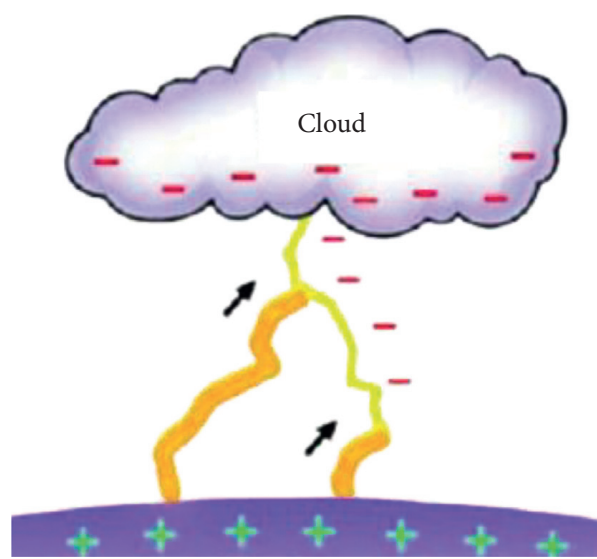

(b)

FIGURE 4: Schematic diagram of lightning pilot (a) and pilot lightning (b) (this picture is quoted from "http://www.baidu.com").

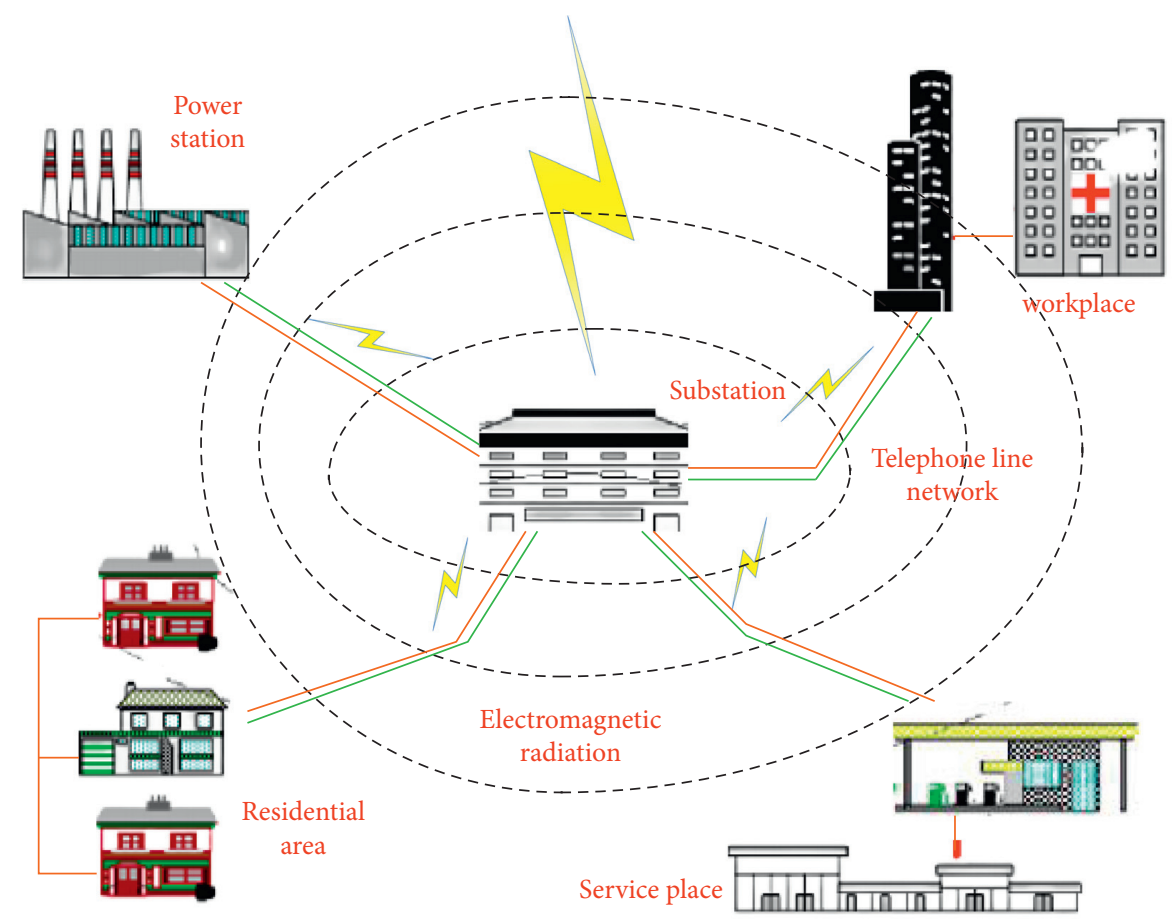

FIGURE 5: The harm caused by lightning to various industries (this picture is quoted from "http://www.baidu.com").

(1) The investigation of lightning failure points in the power system, the early warning of the lightning status near the rocket launch site, the monitoring of the fixed points in the lightning fire zone, the lightning warning in the oil well system, and the monitoring and precise placement of lightning are comparable. It has high practical importance and economic benefits.

(2) Frequent lightning strikes have a wide range of accurate monitoring functions of lightning parameters, so it can deeply study the laws of lightning discharge characteristics, so as to have a more thorough understanding of lightning research and protection and lay the foundation for the basic technology of lightning protection.
(3) The general formation of thunder and lightning is related to strong weather phenomena, such as hurricanes, hail, heavy rain, and tornadoes. If you want to understand the natural causes of these weather changes as soon as possible, you can start by monitoring the range and frequency of lightning activity. This can also be used as an important research method for weather monitoring and forecasting.

(4) In order to reduce the economic loss caused by lightning, the system can be used to monitor the lightning in the environment in real time, analyze and predict the occurrence of lightning and the affected area, and take preventive measures as soon as possible. 


\section{Experiment of Monitoring Data of Lightning Mobile Positioning System}

3.1. Necessity of Lightning Mobile Positioning System. With the development of modern communication technology, high-precision microelectronic products and lightning products have been widely used in the field of communication systems. These microelectronic devices are responsible for measurement and control, protection, communication, and other important functions of the communication system and have obtained huge social and economic benefits. However, when the induced lightning energy suffered by lightning equipment exceeds its protection capability, it will also be damaged. If the lightning recovery system is not repaired and replaced in time, it will cause power outages and other damages that will cause major losses in the transmission system, social and economic property, and human safety, and these are extremely sensitive microelectronics. The device may be damaged. For example, an EMU rear-end collision occurred on July 23, 2011, in Wenzhou, Zhejiang. Lightning hit the railway traction supply chain or nearby ground, passed through the signal cable in a coupled form, and invaded the signal equipment of the station. The error was not repaired in time and eventually caused D3115 and D301 to run backwards, causing 212 casualties, the catastrophic consequences of causing the most damage to the apartment. Therefore, it is very urgent to monitor the operating status of lightning equipment and the lightning environment in real time.

3.2. Sources of Experimental Data. The definition of a storm day is that, regardless of the duration, a storm will occur within a day, and it is recorded as a storm day. Using data from August to September stormy days at 45 stations in Jiangxi Province from 2014 to 2020, the statistical data are broken down into several months and the average number of stormy days from August to September. The downward trend from 2014 to 2020 has all exceeded the significance level of the 0.05 critical line and even exceeded the significance level of 0.01 . The significance level of 0.01 indicates that the number of thunderstorm days in Jiangxi has decreased significantly in August.

3.3. Experimental Research Methods. R/S analysis method is a nonlinear method of scientific prediction. It was first proposed by Hurst, a British hydrology expert, when he was studying hydrological problems on the Nile, and many later developed it to make it more mature. The Hurst index can easily display the trend elements in the time series, and through the value of the Hurst index, you can judge the continuity of the trend elements (relative to sustainability) and summarize the Hurst index ranking, as shown in $\mathrm{Ta}-$ bles 2 and 3.

\section{Monitoring Data of Lightning Mobile Positioning System}

4.1. Experimental Results and Analysis. From Table 4, we can conclude that, in the 7 years, from 2014 to 2020, the number
TABLE 2: Hurst index rating table.

\begin{tabular}{lcc}
\hline Grade & Hurst index range & Sustained strength \\
\hline 1 & $0.50<H \leq 0.55$ & Very weak \\
2 & $0.55<H \leq 0.65$ & Weaker \\
3 & $0.65<H \leq 0.75$ & Stronger \\
4 & $0.75<H \leq 0.80$ & Strong \\
5 & $0.80<H \leq 1.00$ & Very strong \\
\hline
\end{tabular}

TABLE 3: Hurst index rating table.

\begin{tabular}{lcc}
\hline Grade & Hurst index range & Antisustainability strength \\
\hline-1 & $0.45 \leq H<0.50$ & Very weak \\
-2 & $0.35 \leq H<0.45$ & Weaker \\
-3 & $0.25 \leq H<0.35$ & Stronger \\
-4 & $0.20 \leq H<0.25$ & Strong \\
-5 & $0.00 \leq H<0.20$ & Very strong \\
\hline
\end{tabular}

Table 4: Jiangxi Province August-September thunderstorm days' change in years and months.

\begin{tabular}{lccccccc}
\hline $\begin{array}{l}\text { Month } \\
\text { Years }\end{array}$ & 2014 & 2015 & 2016 & 2017 & 2018 & 2019 & 2020 \\
\hline August & 8 & 7 & 12 & 6 & 4 & 6 & 5 \\
September & 7 & 7 & 4 & 6 & 12 & 5 & 4 \\
\hline
\end{tabular}

of stormy days from August to September at 45 stations in Jiangxi Province decreased with the increase of the year. Table 4 shows that the number of stormy days has increased. In August of the 7 years, the number of thunderstorm days in 2016 was the highest and the number of thunderstorm days in 2018 was the lowest. In September, the situation was completely opposite to that in August. The number of thunderstorm days in 2018 was the highest, and the number of thunderstorm days in 2016 was the lowest. The details are shown in Table 4.

It can be seen from Figure 6 that a mutation test was performed on the number of thunderstorm days from August to September and the number of thunderstorm days between months and months, and it was found that there was a sudden change in the number of thunderstorm days in August. It can be seen from the ultrafiltration curve in August that the number of thunderstorm days in Qinghai in May showed a clear downward trend. According to the location of the intersection of the UF and UB curves, it can be determined that the decrease in the number of thunderstorm days in Jiangxi is a sudden change from 2016. The downward trend from 2014 to 2020 has all exceeded the significance level of the 0.05 critical line, and even exceeded the significance level of 0.01 . The significance level of 01 indicates that the number of thunderstorm days in Jiangxi has decreased significantly in August, as shown in Figure 6.

4.2. Forecast of Thunderstorm Trends in Jiangxi Province from August to September. In order to understand the future trend of the total rainstorm days and monthly rainstorm days in Jiangxi Province from August to September, the Hurst index was calculated using the R/S analysis method 


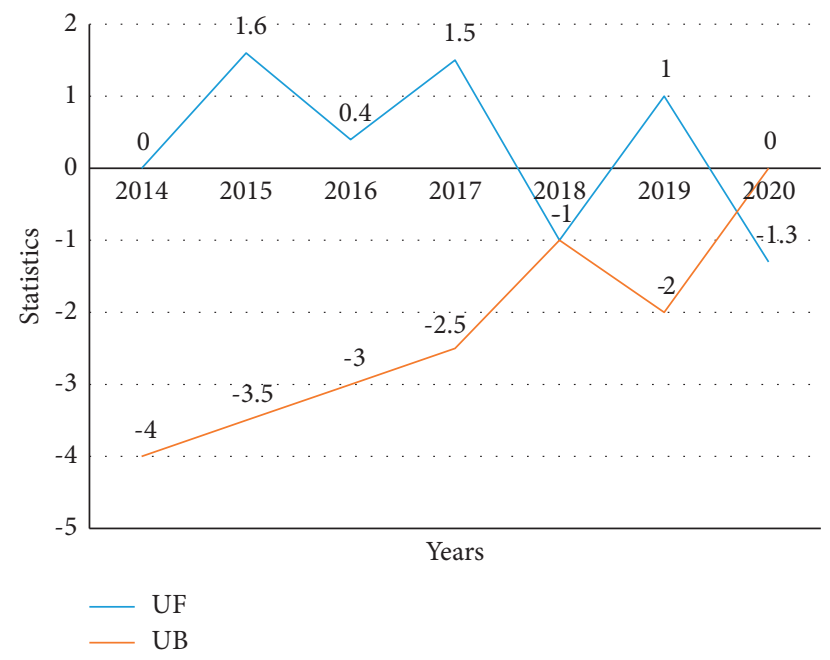

Figure 6: Mann-Kendall statistics curve of August thunderstorm days in Jiangxi Province.

Table 5: Hurst index and classification of thunderstorm days in Qinghai Province.

\begin{tabular}{lccc}
\hline Month & \multicolumn{3}{c}{ Jiangxi Province } \\
& $H$ & Sustained intensity & Grade \\
\hline August & 0.723 & Stronger & 3 \\
September & 0.798 & Strong & 4 \\
Total from August to September & 0.811 & Strong & 4 \\
\hline
\end{tabular}

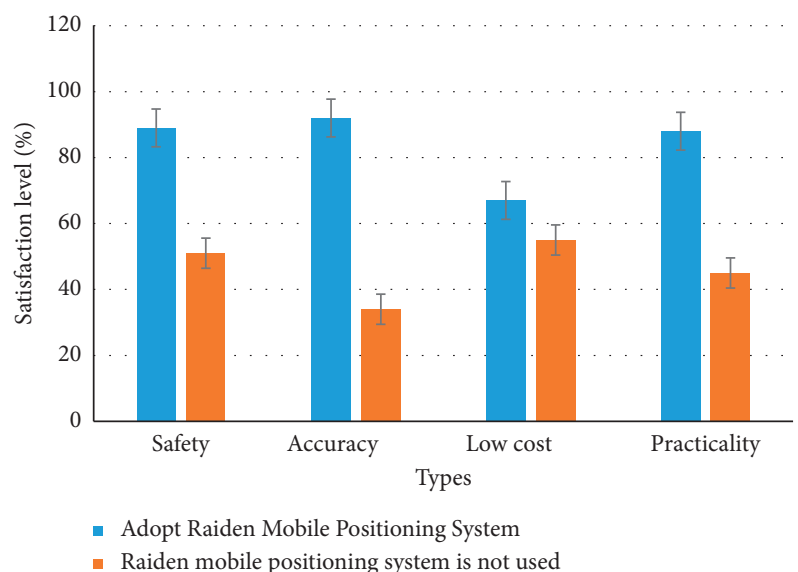

Figure 7: The accuracy of the lightning mobile positioning system.

(see Table 5). As a result, the Hurst index is between 0.5 and 1 , and the storm trend has a strong continuity. According to the Hexcel index, the streak intensity has reached level 5, indicating that the cumulative number of rainstorm days from August to September in Jiangxi Province will maintain a strong downward trend in the future, and the streak intensity is very high.

4.3. Satisfaction Survey of Raiden Mobile Positioning System. We have passed 500 questionnaires, and from Figure 7, we can draw your judgement on the safety, accuracy, low cost, and practicability of the lightning mobile positioning system. At the same time, we can also compare the unused lightning mobile positioning system. Looking at the difference in safety, accuracy, cost, and practicability, we can see that the accuracy of the lightning mobile positioning system has reached $92 \%$. The details are shown in Figure 7.

\section{Conclusion}

With the rapid development of modern technology, especially electronic technology and communication technology, traditional lightning technology is gradually being replaced by new technology. People's understanding of the nature of thunder and lightning continues to increase, and new 
technologies related to lightning placement are constantly emerging. Process and structure of human thunder and lightning have not yet been fully understood. Surveillance and protection technology is far from perfect in this respect, and there is still a lot of work to be done. In short, the lightning mobile positioning system is currently the most advanced and new real-time lightning tracking system. Predicting lightning activities can effectively reduce the damage of lightning to high-tech equipment in the electronic communication system, thereby reducing lightning activities. This article mainly discusses and analyzes the principle, composition, and realization of the lightning positioning system, hoping to lay a good foundation for the innovation and development of the lightning positioning system. Nowadays, the lightning mobile positioning system has been widely used in our country's weather monitoring stations, and it plays a very important role in our national defense lightning strikes and effectively realizes the lightning strike prediction in the monitoring process, which can better enable the competent department to take timely and accurate measures to prevent lightning strikes.

\section{Data Availability}

No data were used to support this study.

\section{Conflicts of Interest}

The authors declare that they have no conflicts of interest.

\section{Acknowledgments}

This work was supported by the Project of Meteorological Science Research of Shandong Meteorological Bureau (the first topic): the research of mountain forest lightning fire risk zoning technology and the research of regional lightning disaster risk assessment method and the development of assessment system.

\section{References}

[1] Y. Dobrev, M. Vossiek, M. Christmann, I. Bilous, and P. Gulden, "Steady delivery: wireless local positioning systems for tracking and autonomous navigation of transport vehicles and mobile robots," IEEE Microwave Magazine, vol. 18, no. 6, pp. 26-37, 2017.

[2] D. Kim, H.-m. Kim, H.-K. Kim, S.-R. Park, K.-S. Lee, and K.-H. Kim, "ThunderPunch: a bare-hand, gesture-based, large interactive display interface with upper-body-part detection in a top view," IEEE Computer Graphics and Applications, vol. 38, no. 5, pp. 100-111, 2018.

[3] S. M. Moosavi, A. Zarrin, A. Mofidi, and S. F. Hosseini, "Investigating the relationship between the frequency of thunderstorms and temperature trend in Mashhad," Geographical Researches Quarterly Journal, vol. 32, no. 3, pp. 74-87, 2017.

[4] K. Martin, T. Arnold, and G. Thomas, "Cb-LIKE - cumulonimbus likelihood: thunderstorm forecasting with fuzzy logic," Meteorologische Zeitschrift, vol. 26, no. 2, pp. 127-145, 2016.
[5] N. V. Baranovskiy, "The development of application to software origin pro for informational analysis and forecast of forest fire danger caused by thunderstorm activity," Journal of Automation and Information Sciences, vol. 51, no. 4, pp. 1223, 2019.

[6] S. Singh and L. Yan, "A cloud service architecture for analyzing big monitoring data," Tsinghua Science and Technology, vol. 21, no. 01, pp. 55-70, 2016.

[7] L. Lombardi, M. Nocentini, W. Frodella et al., "The Calatabiano landslide (southern Italy): preliminary GB-InSAR monitoring data and remote 3D mapping," Landslides, vol. 14, no. 2, pp. 685-696, 2017.

[8] R. L. Irvine, J. L. Thorley, and R. Westcott, "Why do fish strand? an analysis of ten years of flow reduction monitoring data from the Columbia and Kootenay rivers, Canada," River Research and Applications, vol. 31, no. 10, pp. 1242-1250, 2016.

[9] M. E. Sather and K. Cavender, "Trends analyses of 30 years of ambient 8 hour ozone and precursor monitoring data in the South Central U.S.: progress and challenges," Environmental Sciences: Processes \& Impacts, vol. 18, no. 7, pp. 819-831, 2016.

[10] E. Kumpel, R. Peletz, M. Bonham, and R. Khush, "Assessing drinking water quality and water safety management in subsaharan africa using regulated monitoring data," Environmental Science \& Technology, vol. 50, no. 20, pp. 10869-10876, 2016.

[11] M. Görges, N. C. West, and S. D. Whyte, "Using physiological monitoring data for performance feedback: an initiative using thermoregulation metrics," Canadian Journal of Anesthesial Journal Canadien D'anesthésie, vol. 64, no. 3, pp. 245-251, 2017.

[12] D. L. Wagner, S. M. Hammerschmidt-Snidarich, C. A. Espin, K. Seifert, and K. L. McMaster, "Pre-service teachers' interpretation of CBM progress monitoring data," Learning Disabilities Research \& Practice, vol. 32, no. 1, pp. 22-31, 2017.

[13] M. C. Zwart, P. Robson, and S. Rankin, "Using environmental impact assessment and post-construction monitoring data to inform wind energy developments," Ecosphere, vol. 6, no. 2, pp. 1-11, 2016.

[14] E. Hénin, M. Bergstrand, W. Weitschies, and M. O. Karlsson, "Meta-analysis of magnetic marker monitoring data to characterize the movement of single unit dosage forms though the gastrointestinal tract under fed and fasting conditions," Pharmaceutical Research, vol. 33, no. 3, pp. 751-762, 2016.

[15] C. T. A. Moermond and C. E. Smit, "Derivation of water quality standards for carbamazepine, metoprolol, and metformin and comparison with monitoring data," Environmental Toxicology and Chemistry, vol. 35, no. 4, pp. 882-888, 2016.

[16] S. M. Blair, C. D. Booth, G. Williamson, A. Poralis, and V. Turnham, "Automatically detecting and correcting errors in power quality monitoring data," IEEE Transactions on Power Delivery, vol. 32, no. 2, pp. 1005-1013, 2017.

[17] A. Bhlandt and R. Schierl, "Benefits of wipe sampling: evaluation of long-term 5-fluorouracil and platinum monitoring data," Pharmaceutical Technology in Hospital Pharmacy, vol. 1, no. 3, pp. 139-150, 2016.

[18] M. Hravnak, L. Chen, A. Dubrawski, E. Bose, G. Clermont, and M. R. Pinsky, "Real alerts and artifact classification in archived multi-signal vital sign monitoring data: implications for mining big data," Journal of Clinical Monitoring and Computing, vol. 30, no. 6, pp. 875-888, 2016.

[19] R. Lou, W. Wang, X. Li, Y. Zheng, and Z. Lv, "Prediction of ocean wave height suitable for ship autopilot," IEEE 
Transactions on Intelligent Transportation Systems, vol. 59, pp. 1-10, 2021.

[20] X. W. Ye, Y. H. Su, P. S. Xi, B. Chen, and J. P. Han, "Statistical analysis and probabilistic modeling of WIM monitoring data of an instrumented arch bridge," Smart Structures and Systems, vol. 17, no. 6, pp. 1087-1105, 2016.

[21] H.-Y. Cho, K.-S. Lee, and S.-M. Ahn, "Impact of outliers on the statistical measures of the environmental monitoring data in Busan coastal sea," Ocean and Polar Research, vol. 38, no. 2, pp. 149-159, 2016.

[22] O. I. Podymov and A. G. Zatsepin, "Seasonal anomalies of water salinity in the Gelendzhik region of the Black Sea according to shipborne monitoring data," Oceanology, vol. 56, no. 3, pp. 342-354, 2016.

[23] B. Robert, Corrigendum to "Back-analysing rock mass modulus from monitoring data of two tunnels in Sydney, Australia," Journal of Rock Mechanics and Geotechnical Engineering, vol. 10, no. 1, pp. 195-196, 2017.

[24] R. Bertuzzi, "Back-analysing rock mass modulus from monitoring data of two tunnels in Sydney, Australia," Journal of Rock Mechanics and Geotechnical Engineering, vol. 9, no. 5, pp. 877-891, 2017.

[25] C. Steiakakis, Z. Agioutantis, and E. Apostolou, "Integrating weather and geotechnical monitoring data for assessing the stability of large scale surface mining operations," Open Geosciences, vol. 8, no. 1, pp. 694-699, 2016.

[26] H. Su, Z. Wen, and Z. Chen, "Dam safety prediction model considering chaotic characteristics in prototype monitoring data series," Structural Health Monitoring, vol. 15, no. 6, pp. 629-639, 2016. 